MATEC Web of Conferences 9, 03007 (2013)

DOI: $10.1051 /$ matecconf/20130903007

(C) Owned by the authors, published by EDP Sciences, 2013

\title{
A qualitative investigation on double-skin façade fires
}

\author{
C.L. Chow
}

\author{
Department of Civil and Architectural Engineering, City University of Hong Kong, Tat Chee \\ Avenue, Kowloon, Hong Kong
}

\begin{abstract}
Fire hazard of the green architectural feature double-skin façade is always a concern. A hazard scenario with a room fire adjacent to the façade was identified earlier after interviewing with fire professionals. Experimental studies on the consequence of the fire hazard due to trapping heat and mass in the façade cavity carried out before will be reported in this presentation. The rig was of height $15 \mathrm{~m}$ with a fire chamber placed next to it. Flashover was induced to direct hot flame and smoke out. Only part of the building was studied instead of a full height façade due to resource limitations. Air temperature next to the upper interior glass pane was confirmed to be higher than the air temperature next to the exterior pane with normal air cavity depth in double-skin façades. Flame will then be diverted to the interior glass pane, giving possibility to spread fire to the upper rooms.
\end{abstract}

\section{INTRODUCTION}

Architectural feature double-skin façade (DSF) can give a better indoor visual environment as glass façade buildings have less solar heat gain or loss [1]. Two glass panes separated by up to $2 \mathrm{~m}$ are installed parallel to each other. This gives an air cavity between to take out solar heat by natural convection. However, fire safety for DSF is a concern that should be dealt with carefully [2]. A scenario of having a post-flashover room fire next to the DSF as in Figure 1 was identified after interviewing with fire professionals. The key hazards of trapping heat and mass in the façade cavity were identified from earlier computer simulations [3]. Air temperature next to the interior glass pane is found to be higher than the air temperature next to the exterior pane with wide air cavity depth from the numerical studies.

Full-scale burning tests on DSF fires were carried out to verify the above. Part of a multistory DSF was constructed at the burning site at a remote area of Northern China in Harbin, Heilongjiang, China. A $15 \mathrm{~m}$ tall rig was erected as in Figure 1 . Cavity depths of $1 \mathrm{~m}, 1.5 \mathrm{~m}$ and $2.5 \mathrm{~m}$ were studied. The rig design was based on flame bending along the building façade $[4,5]$. Typical testing results are reported $[6,7]$ separately. This presentation will report some results of the experiments.

The study focused on measuring the hot air temperature to understand the air flow pattern inside the façade cavity. Air temperatures next to the interior and exterior panes in the façade cavity were measured. The type and material features of the glass panes are not the subject of interest. Different glass panes would have different physical and thermal properties, and it is difficult to deduce general results. Therefore, only air temperatures near the façade skins were recorded rather than the surface temperatures of glass. Possible fire hazard can then be identified qualitatively [1] with some results reported in this presentation.

\section{ROOM FIRE SCENARIO}

There are interests in understanding fire spread from an adjacent room along the façade [8-10]. The fire scenario identified is to have a model room constructed next to the façade [8-10] as in Figure 1 with

This is an Open Access article distributed under the terms of the Creative Commons Attribution License 2.0, which permits unrestricted use, distribution, and reproduction in any medium, provided the original work is properly cited. 


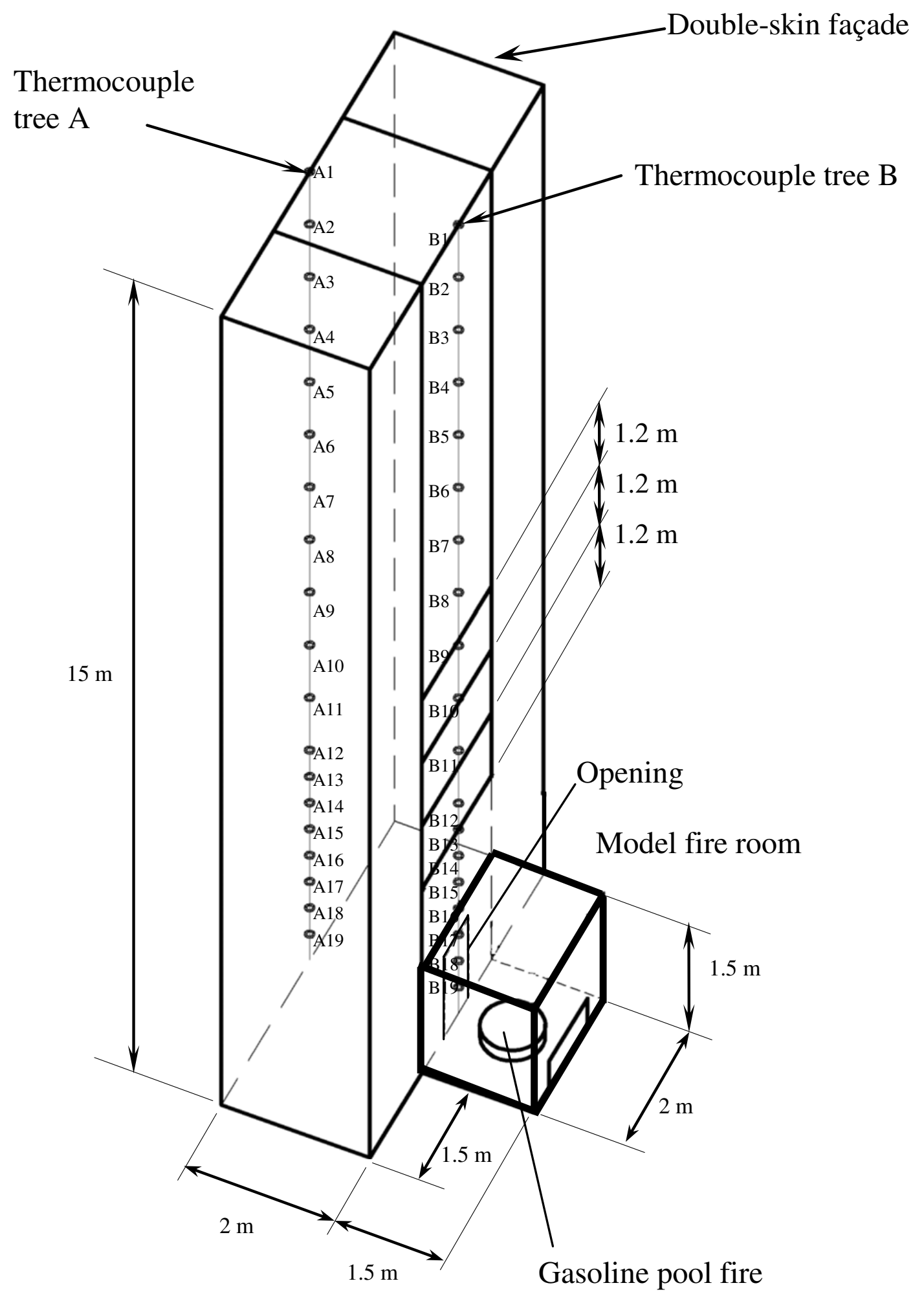

Figure 1. Schematic diagram of the DSF rig. 
$1^{\text {st }}$ International Seminar for Fire Safety of Facades, Paris (France), 2013

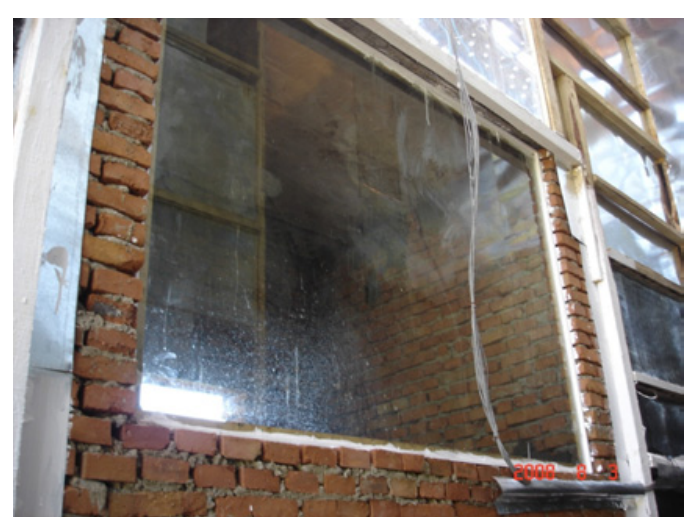

(a) Opening

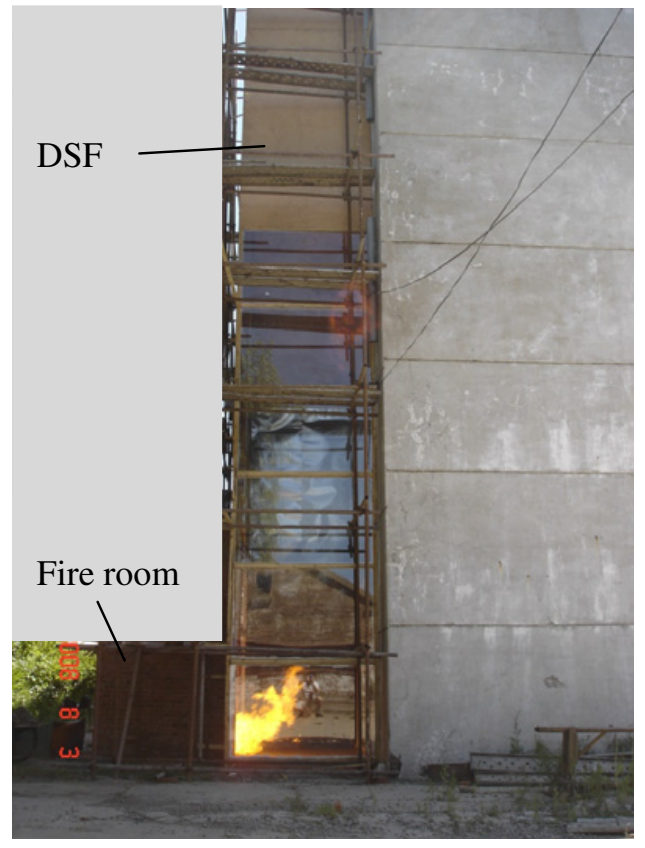

(b) Flame driving out

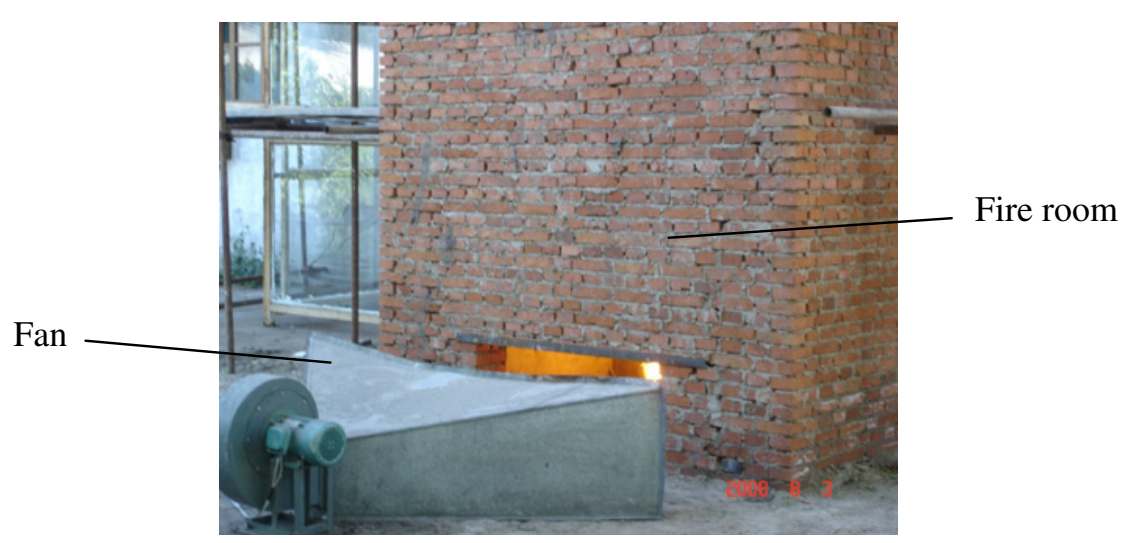

(c) Back of fire room

Figure 2. The fire room in the tests.

pictures in Figure 2a to c. Flashover was induced in the model room to drive flame out of the opening. The window jet would then act on the upper façade.

Note that a smaller room was used in some testing standards [11-15] as in Figure 3. But in this design, it is difficult to control the window jet. This is different from the arrangement designed in testing façade in this paper based on a method developed before [8-10].

In this arrangement, the room fire was set up by a gasoline pool fire. This is different from burning wood cribs as in the literature [11-15]. This will give a more uniform heat release rate in the postflashover room fire. A fan was placed at the back as in Figure $2 b$ to drive the hot flame out of the opening when necessary as in Figure 2c. 


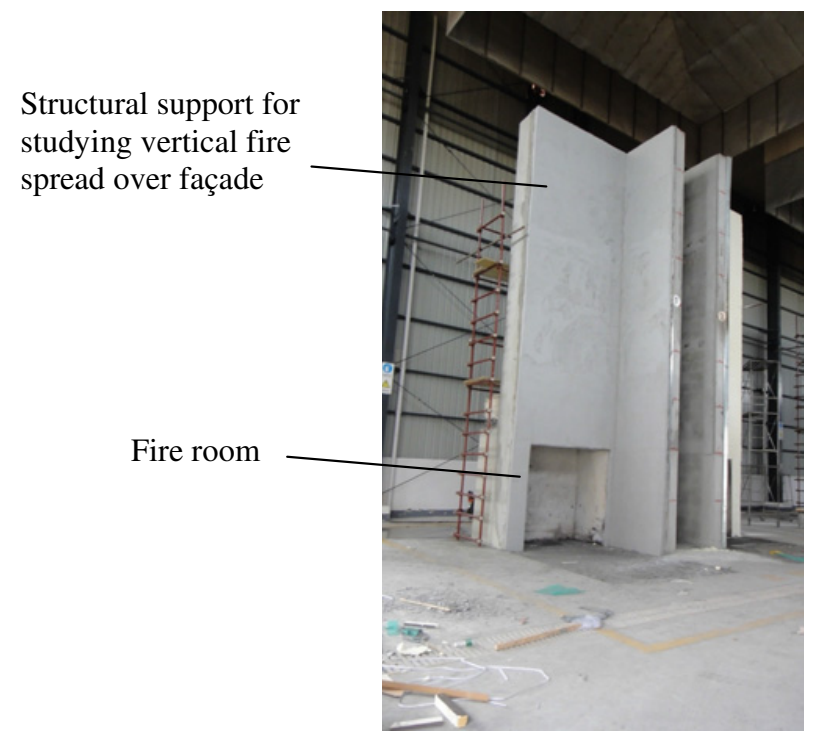

Figure 3. New tests proposed in GB (2013).

Table 1. Full-scale experiments.

\begin{tabular}{|c|c|}
\hline Test number & Cavity depth / m \\
\cline { 1 - 1 } DSN-1 & \multirow{2}{*}{2} \\
\cline { 1 - 1 } DSN-2 & \\
\cline { 1 - 1 } DSN-3 & \\
\cline { 1 - 1 } DSN-4 & \multirow{2}{*}{1.5} \\
\cline { 1 - 1 } DSN-5 & \\
\cline { 1 - 1 } DSN-6 & \\
\cline { 1 - 1 } DSN-7 & \\
\cline { 1 - 1 } DSN-8 & \\
\cline { 1 - 1 } DSN-9 & \\
\hline
\end{tabular}

\section{FULL-SCALE BURNING TESTS}

Experiments were focused on studying air temperatures at positions adjacent to the interior and exterior pane of the façade cavity. Measured data on air temperatures would be more accurate in understanding the air flow pattern. Results on the relative air temperatures adjacent to the two panes are useful for justifying the identified fire hazard.

Nine full-scale burning tests carried out in the experimental rig will be reported in this presentation. These tests are labeled DSN-1 to DSN-9. All three side walls of the façade were enclosed.

The cavity depths were built as $2 \mathrm{~m}, 1.5 \mathrm{~m}$ and $1 \mathrm{~m}$. A summary of the testing conditions is shown in Table 1. Tests DSN-1 to DSN-3 were for cavity depth of $2 \mathrm{~m}, \mathrm{DSN}-4$ to DSN-6 for $1.5 \mathrm{~m}$ and DSN-7 to DSN-9 for $1 \mathrm{~m}$, all three sides were enclosed by glass.

A fire chamber was placed at the fire room as shown in the figure. The pool fire at the fire chamber was $0.81 \mathrm{~m}$ in diameter with $10,000 \mathrm{ml}$ of gasoline. The heat release rate of the pool fire was measured separately while burning by itself in the oxygen consumption calorimeter. 


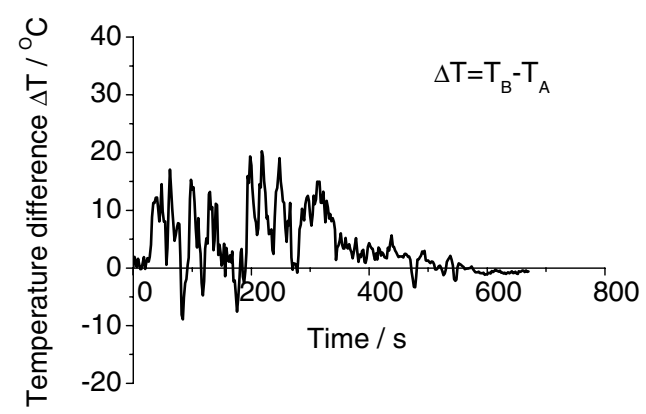

(a) A1 and B1

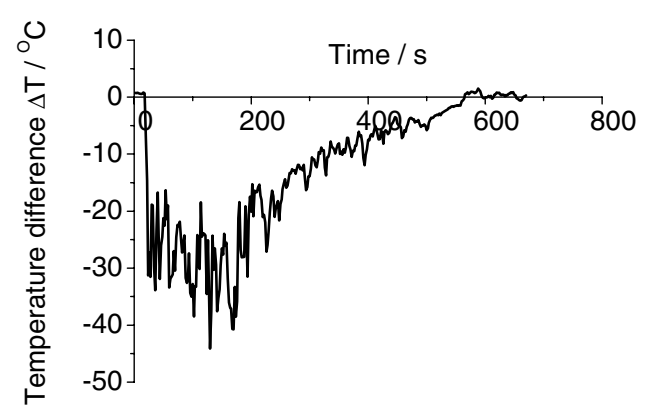

(b) A10 and B10

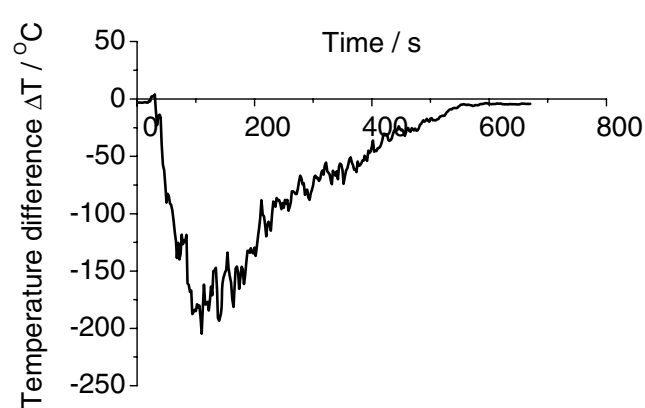

(c) A16 and B16

Figure 4. Temperature difference at high, middle and low levels for test DSN-1.

\section{RESULTS}

Air temperature difference $\Delta T$ between the values $T_{A}$ and $T_{B}$ measured at positions near to exterior (A) and interior (B) panes are given by the following equation in studying the three fire hazards:

$$
\Delta T=T_{B}-T_{A}
$$

Details of the testing results are described by Chow [2, 6, 7]. Typical results on air temperature difference $\Delta T$ for DSN-1 at high level (A1 and B1), middle level (A10 and B10), and low level (A16 and B16) are shown in Figure 4.

Test results for each condition on cavity depth, fire size, fan operation and others are consistent, repeatability of the experiment is consistent. Air temperature difference between thermocouples next to interior and exterior at same heights are similar for cavity depth of $1 \mathrm{~m}$.

\section{FIRE HAZARD OF DSF}

Average air temperature profiles next to the interior and exterior panes for the 9 tests are plotted in Figure 5. It is observed that air temperatures next to the interior pane are higher than the ones next to 
MATEC Web of Conferences

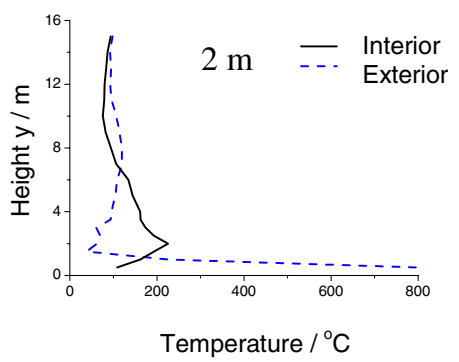

(a) Test DSN-1 at $350 \mathrm{~s}$

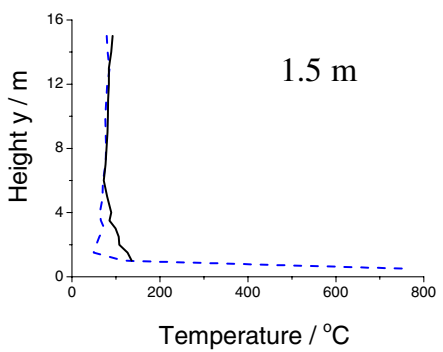

(d) Test DSN-4 at $300 \mathrm{~s}$

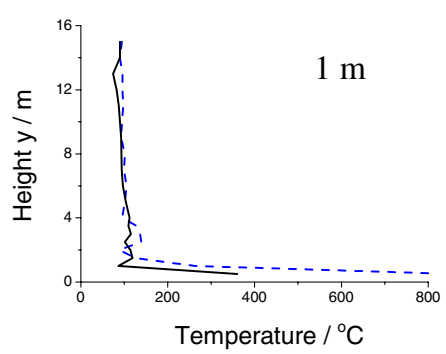

(g) Test DSN-7 at $550 \mathrm{~s}$

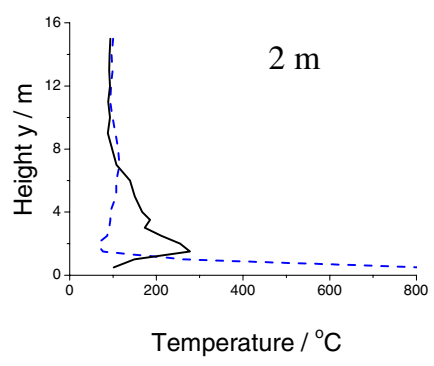

(b) Test DSN-2 at $350 \mathrm{~s}$

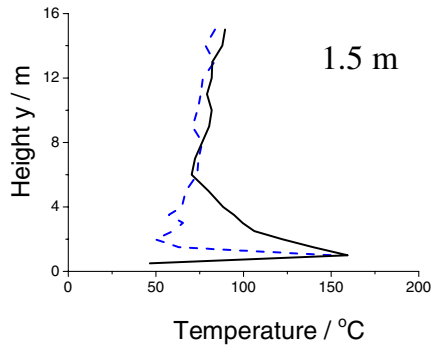

(e) Test DSN-5 at $650 \mathrm{~s}$

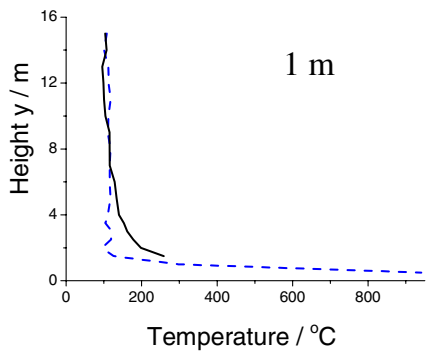

(h) Test DSN-8 at $450 \mathrm{~s}$

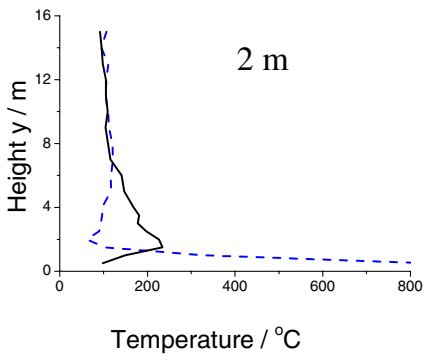

(c) Test DSN-3 at $350 \mathrm{~s}$

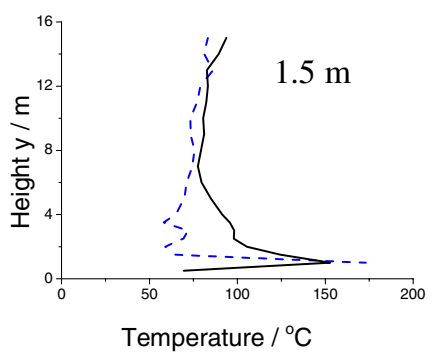

(f) Test DSN-6 at $550 \mathrm{~s}$

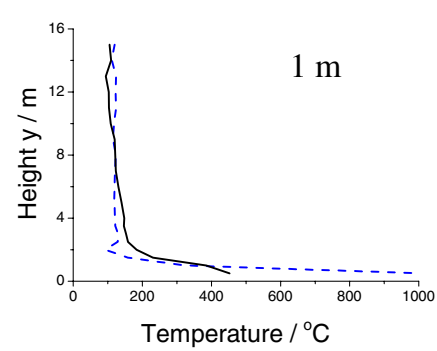

(i) Test DSN-9 at $400 \mathrm{~s}$

Figure 5. Vertical air temperature profiles for the 9 tests.

the exterior pane. It can be explained as proposed earlier $[2,3]$ with a practical presentation shown in Figure 6 as following:

Window flame plume [16, 17] driven out by the room flashover fire acted on the exterior pane first. However, air entrainment at upper level is higher than at the lower part of the plume. Therefore, flame plume detached from the exterior pane. Eventually, the flame diverted to act on the upper level of the interior pane.

These observations are clearly indicated by the vertical temperature profiles of tests DSN-1 to DSN6 with cavity depths of $2 \mathrm{~m}$ and $1.5 \mathrm{~m}[2,6,7]$ as shown in Figure 5a to f.

The above findings are very useful for designing fire safety provisions of DSF. The possible hazard is highlighted in Figure 6 which may occur inside the façade cavity for normal cavity depth. 
$1^{\text {st }}$ International Seminar for Fire Safety of Facades, Paris (France), 2013

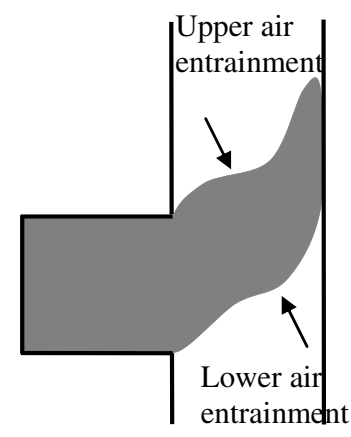

(a) Acting on exterior pane

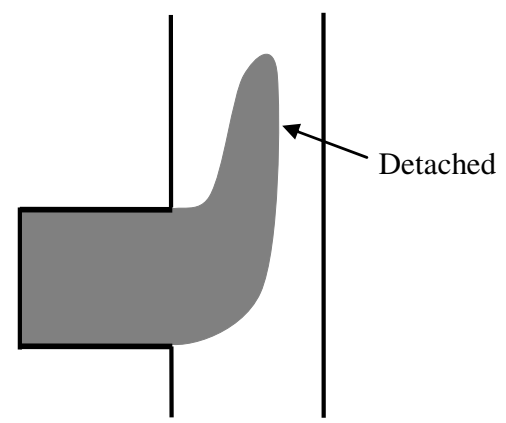

(b) Detached from exterior pane

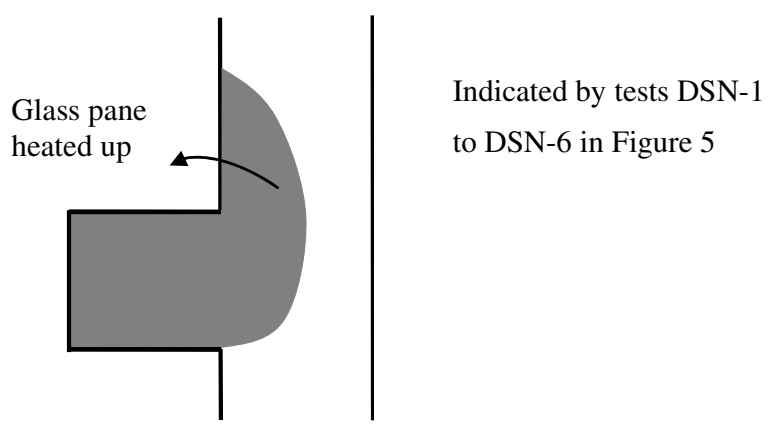

(c) Attached to interior pane

Figure 6. Possible flame spread for normal cavity depth proposed earlier by Chow (2009).

\section{CONCLUSION}

The possible hazard that may occur inside the façade cavity in case of a room fire was reported qualitatively in this paper. The façade cavity depth of a DSF is proposed to be a key factor for fire hazards. 


\section{MATEC Web of Conferences}

The experimental data can be applied to derive empirical equations on correlating the air temperature in the air cavity with other key parameters such as the façade cavity depth. The results can be used for setting up codes or acceptance criteria on performance-based design [18] for protecting against DSF fires. Finally, this is a presentation reporting the DSF fire tests carried out in the past years. All the experimental details and raw data had been reported in the literature $[2,6,7]$.

\section{References}

[1] Lstiburek, J.W., "Why Green can be Wash", ASHRAE Journal, 50 (11), 28-36, 2008.

[2] Chow, C.L., "Assessment of Fire Hazard on Glass Buildings with an Emphasis on Doubleskin Façades", PhD dissertation, Department of Architecture, University of Cambridge, UK, 2009.

[3] Chow, C.L., "Numerical Simulations on Airflow to the Double-skin Façade Cavity by an Adjacent Room Fire", Proceedings of the ASME 2010 International Mechanical Engineering Congress and Exposition, Vol. 5, pp. 439-448, Paper no. IMECE2010-37478, Vancouver, British Columbia, Canada, 12-18 November, 2010.

[4] Oleszkiewicz, I., "Fire Exposure to Exterior Walls and Flame Spread on Combustible Cladding", Fire Technology, November, 357-375, 1990.

[5] Klopovic, S., and Turan, Ö.F., "Flames Venting Externally During Full-scale Flashover Fires: Two Sample Ventilation Cases", Fire Safety Journal, 31 (2), 117-142, 1998.

[6] Chow, C.L., Gao, Y., and Dong, H., "Selected Experimental Data Compiled from Full-scale Burning Tests on Glass Double-skin Façade Systems”, International Journal on Engineering Performance-based Fire Codes, Accepted to publish, 2012.

[7] Chow, C.L., Gao, Y., and Dong, H., "Full-scale Burning Tests on Glass Double-skin Façade Systems", ASCE Texas Section Centennial Fall Conference 2013, 11-14 September 2013, Dallas, Texas, USA - Accepted to present.

[8] Chow, W.K., Hung, W.Y., Gao, Y., Zou, G., and Dong, H., "Experimental Study on Smoke Movement Leading to Glass Damages in Double-skinned Façade", Construction and Building Materials, 21 (3), 556-566, 2007.

[9] Chow, W.K., and Hung, W.Y., "Effect of Cavity Depth on Smoke Spreading of Double-skin Facade", Building and Environment, 41 (7), 970-979, 2006.

[10] Chow, C.L., Chow, W.K., Han, S.S., and So, A.K.W., "Vertical Air Temperature Profiles in a Single Skin Glass Façade with a 'Jumping Fire' Scenario", Journal of Applied Fire Science, 17 (2), 107-130, 2007-2008.

[11] British Standard BS8414-1:2002, Fire Performance of External Cladding Systems - Part 1: Test Method for Non-loadbearing External Cladding Systems Applied to the Face of the Building, British Standards Institution, UK, 2002.

[12] British Standard BS8414-2:2005, Fire Performance of External Cladding Systems - Part 2: Test Method for Non-loadbearing External Cladding Systems Fixed to and Supported by a Structural Steel Frame, British Standards Institution, UK, 2005.

[13] Loss Prevention Standard LPS 1581: Issue 2.0, Requirements and Tests for LPCB Approval of Non-load Bearing External Cladding Systems Applied to the Masonry Face of a Building, BRE Global Ltd., 2010.

[14] Colwell, S., and Baker, T., Fire Performance of External Thermal Insulation for Walls of Multistory Buildings, $3^{\text {rd }}$ Edition, Building Research Establishment Report BR135, UK, 2013.

[15] GB/T29416-2012, Fire Tests on External Building Façade, Chinese Standard, Beijing, implemented from 1 October 2012. 
$1^{\text {st }}$ International Seminar for Fire Safety of Facades, Paris (France), 2013

[16] Seigel, L.G., "The Projection of Flames from Burning Buildings", Fire Technology, 5, 43-51, 1969.

[17] Thomas, P.H., and Law, M., "The Projection of Flames from Buildings on Fire", Fire Prevention Science and Technology, 10, 19-26, 1972.

[18] Chow, W.K., "Experience on Implementing Performance-based Design in Hong Kong”, Welcome speech, The 9th Asia-Oceania Symposium on Fire Science and Technology, Hefei, China, 17-20 October, 2012. 